\title{
Research on solar water heating system based on TRNSYS simulation optimization
}

In this paper, the typical system of solar energy system: natural circulation system and forced circulation system are analyzed. The two systems are simulated on the TRNSYS platform, and the configuration of the system itself has been discussed. The purpose is to provide reference for the scientific implementation of solar energy architecture integration. On the basis of summarizing the solar energy construction technology, the natural circulation system and the forced circulation system of solar hot water system have been discussed emphatically. The simulation experiment is designed on the TRNSYS platform. The influence of different heat collection area and water tank volume on solar energy guarantee rate and system efficiency has been discussed by simulation data. Finally, the optimal allocation scheme of natural constraints of natural circulation and forced circulation has been obtained.

Keywords: TRNSYS platform; solar fraction; system efficiency; heat collector area; water tank volume

\subsection{Introduction}

$\mathrm{E}$ nergy is an important cornerstone for human survival, as well as essential for economic development. The sustainable development of energy has attracted the attention of people all over the world. How human beings will face the problem of the depletion of non-renewable resources has become the focus of the study of relevant scholars or departments. Therefore, more attention has been paid to the development of new energy, the utilization efficiency of renewable resources, and the utilization of solar energy as one of the most important energy sources.

The solar water heating system studied in this paper is a passive solar building in the field of architecture. If divided according to the way solar energy is obtained, it can be

Blind peer reviews carried out

Messrs. Yan Yan, Liyan Zhang, Yuhan Li, Xiangyu Xu, Zhencheng Jiang and Feiyu Cheng, Hebei Key Laboratory of Data Science and Applications, Engineering Computing and Simulation Innovation Laboratory, North China University of Science and Technology, Tangshan, 063000, China. Correspondence: Liyan Zhang, Email: yanjxky@126.com divided into direct access technology, indirect acquisition technology and mixed technology. But whatever the access technology is chosen, the five basic elements shown in Fig.1 are needed.

The key to the solar hot water system is heat collector system, and the heat collector system uses active solar building technology, comprising a vertical wall, the flashing and the support frame. Pneumatic conveying system comprises a fan and pipeline. The operational principle is shown in Fig.2 of the solar wall.

According to the operation mode of solar water heating system, it can be divided into natural circulation system, series-connected system and forced circulation system. Among them, the natural circulation system refers to the use of solar energy to heat the refrigerant in the system between the collector and the heat storage water tank; The seriesconnected system refers to the use of a controller to allow the heat transfer medium to flow directly through the collector's heating system under the action of tap water pressure or other additional power. Forced circulation system refers to a system that uses a temperature difference controller and a circulating water pump to cause the system to cycle the heat transfer medium to the heat of the heat collection system.

1. The natural circulation system is usually divided into two types. One is the natural circulation system shown in the left in Fig.3, the other is natural circulation constant temperature drainage system as shown in the right in Fig.3.

2. The series-connected system is usually controlled by constant flow and constant temperature. When the storage temperature reaches the set temperature, the water valve is opened, and the hot water in the heat collector system flows into the heat storage tank. When the water temperature of the collector system is lower than the set temperature, the water valve is closed, and the supplementary cold water stays in the heat collector system to absorb the solar energy. The series-connected system can use non-pressure heat collector, and the collector system has lower cost. It is used more and more 


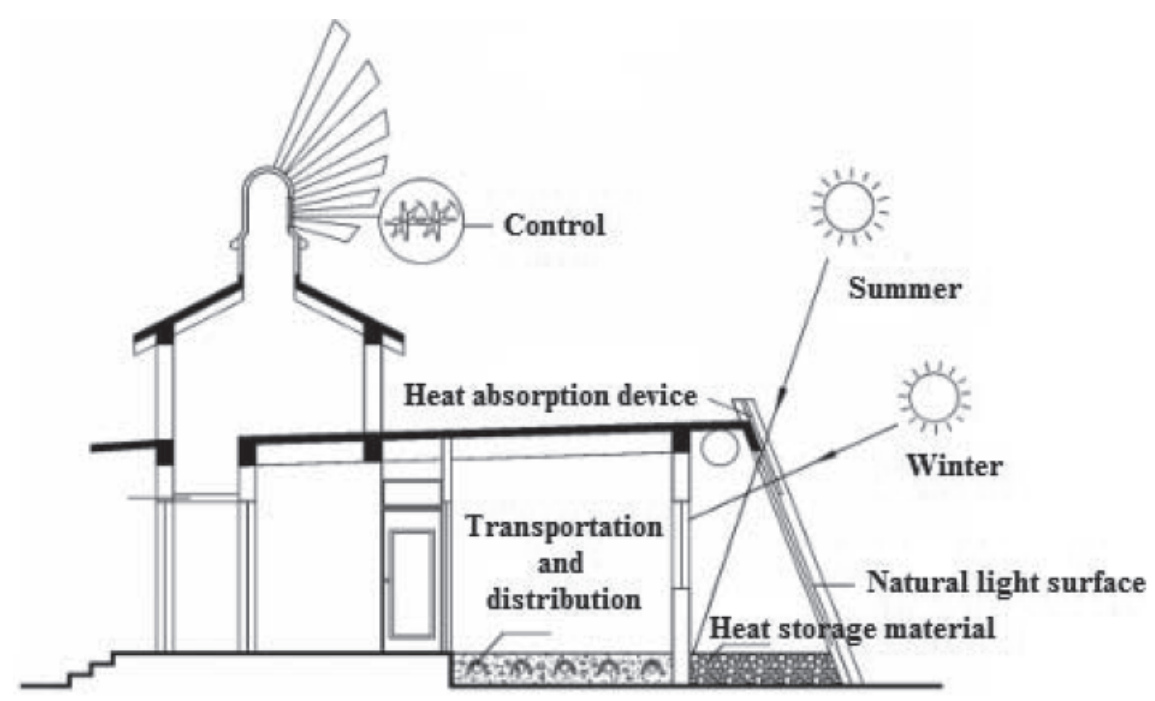

Fig.1: Sketch of the five elements of passive solar energy utilization

Fan powered by photovoltaic cells

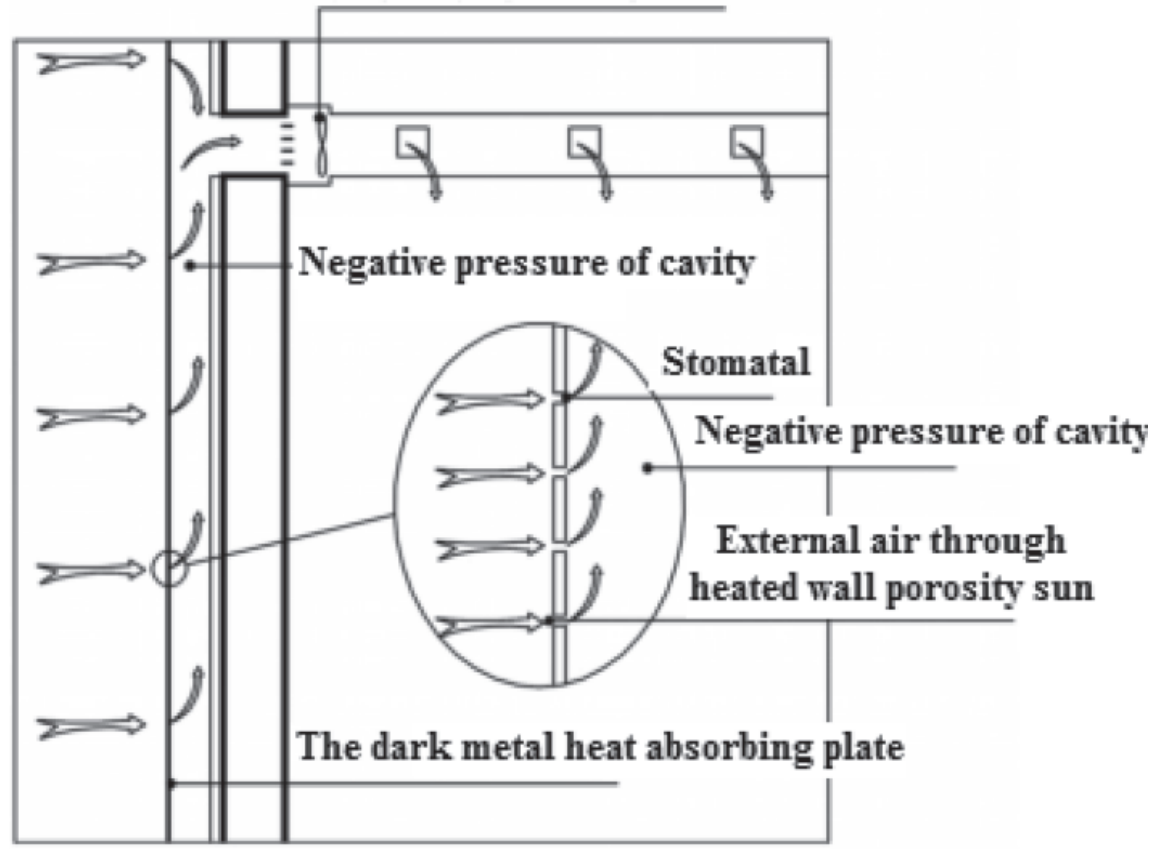

Fig.2: Schematic diagram of solar wall working principle

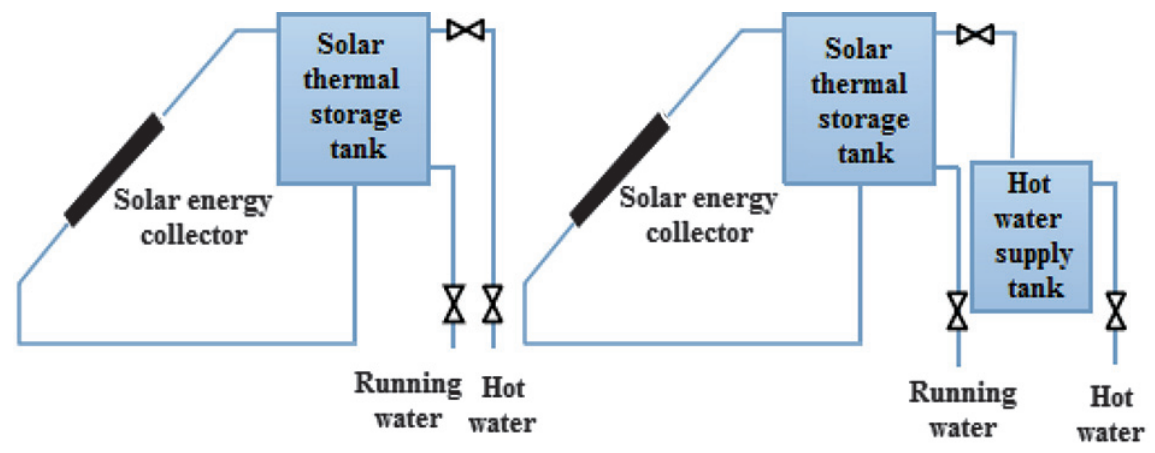

Fig.3: Natural circulation system and natural circulation constant temperature drainage system in small and medium-sized buildings in China.

3. There are many forms of forced circulation system, mainly two kinds, direct and indirect. Among them: the direct system is mainly divided into single tank and double tank; The indirect system can also be divided into single tank and double tank. As shown in Fig.4, the direct forced circulation system (left is a single tank, and the right is a double tank), as shown in Fig.5, the indirect forced system (the left is a single tank, the right is a double tank).

Many efforts have been made to study the combination of solar energy with buildings and the improvement of their efficiency. Among them: Xiao Chang $\mathrm{Yu}$ (2008) pointed out that energy is the basic factor for human survival and development, and coal is from the total amount of energy which will gradually decrease and dry up. Therefore, developing solar energy, wind energy, geothermal and other renewable resources are imperative and imminent, and the buildings in the construction and use of energy consumption not only account for about $30 \%$ of total consumption, but also cause environmental pollution [1]. Wu JinLong (2014) pointed out that the solar energy, as the leader of the use of new energy in the process, makes a great contribution in alleviating the energy crisis in the world. Besides, for housing construction plays an important role in the field of the traditional high energy consumption, strengthening the application of solar energy in building engineering will have a greater energy efficiency, environmental protection and economic benefits [2]. Long YunTao (2014) discussed the feasibility of the implementation of solar construction integration in Northern Shaanxi, and the application prospect of solar building in Northern Shaanxi Province were analyzed by the north of Shaanxi geographical location, climate change, the distribution of solar energy resources and the current situation of residential housing conditions of the research [3]. Ren Naixin 

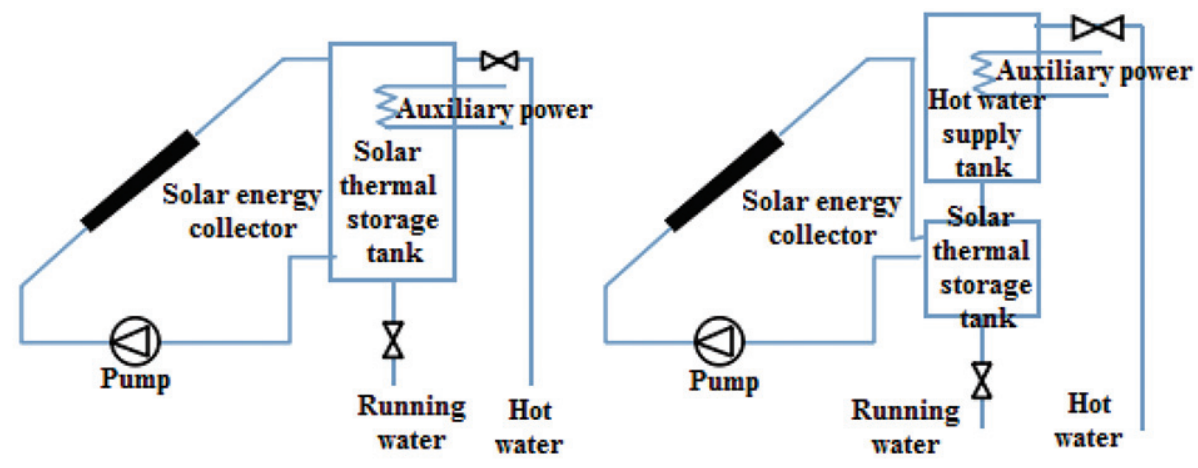

Fig.4: Direct forced circulation system (left is single tank, right is double tank)
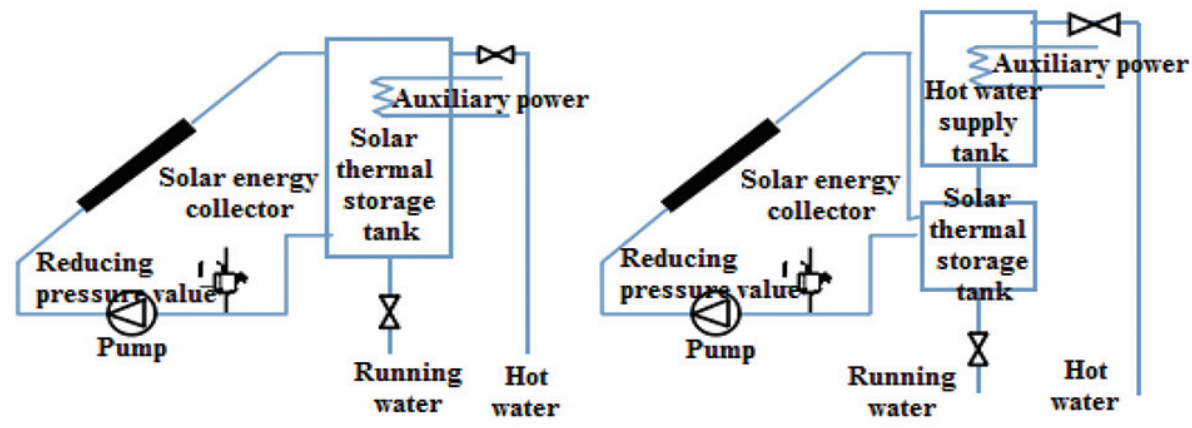

Fig.5: Indirect forced circulation system (left is single tank, right is double tank)

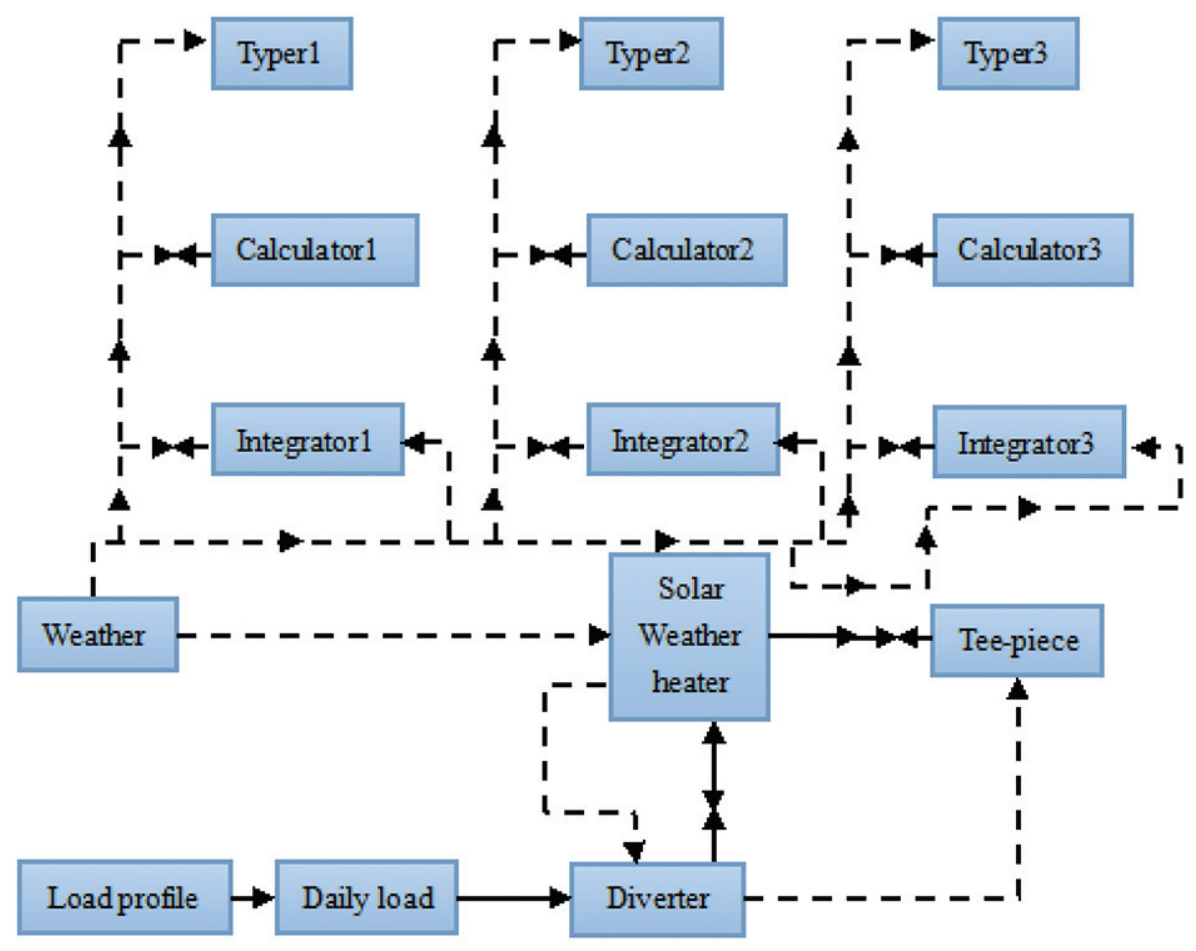

Fig.6: Natural loop structure diagram in TRNSYS

(2011) pointed out that solar energy is also called solar radiation and sent from the sun into universe in a form of electromagnetic radiation energy. And solar building can be divided into passive solar building and active solar building, among which the former directly uses solar energy sufficient for the construction of space heating, lighting and ventilation, and the latter indirectly uses solar energy, photovoltaic power generation equipment through building space lighting, heating, ventilation, refrigeration, and provide the solar hot water and solar air conditioner [4].

The main content of this article is the optimization of solar water heating system. The tool used is TRNSYS software. The purpose is to provide some theoretical support for building energy efficiency. The main content of this chapter is the technical problems of solar energy building, the purpose of which is to lay the foundation for the optimization of solar hot water system.

\subsection{Optimization experiment analysis of solar water heating system}

\subsection{EXPERIMENTAL ANALYSIS ON \\ OPTIMIZATION OF NATURAL CIRCULATION SYSTEM}

The efficiency of solar water heating system is affected by many factors. Besides by natural factors such as radiation, environmental temperature and so on, it is also affected by the system itself. This article considers that the efficiency of natural circulation solar water heating system is mainly related to the collector area and the water tank volume. The TRNSYS platform can implement the simulation of the natural circulation system, so the appropriate model can be found from the module library of TRNSYS, and simulate the circulatory system, as shown in Fig.6 of the natural cycle structure of TRNSYS.

For the system discussed in this article, the number of water users is set at 3 , the daily water consumption is 50L (per person per day), and the outlet water temperature is 50 degrees Celsius. The collector adopts the copper and aluminum composite plate core common plate heat 


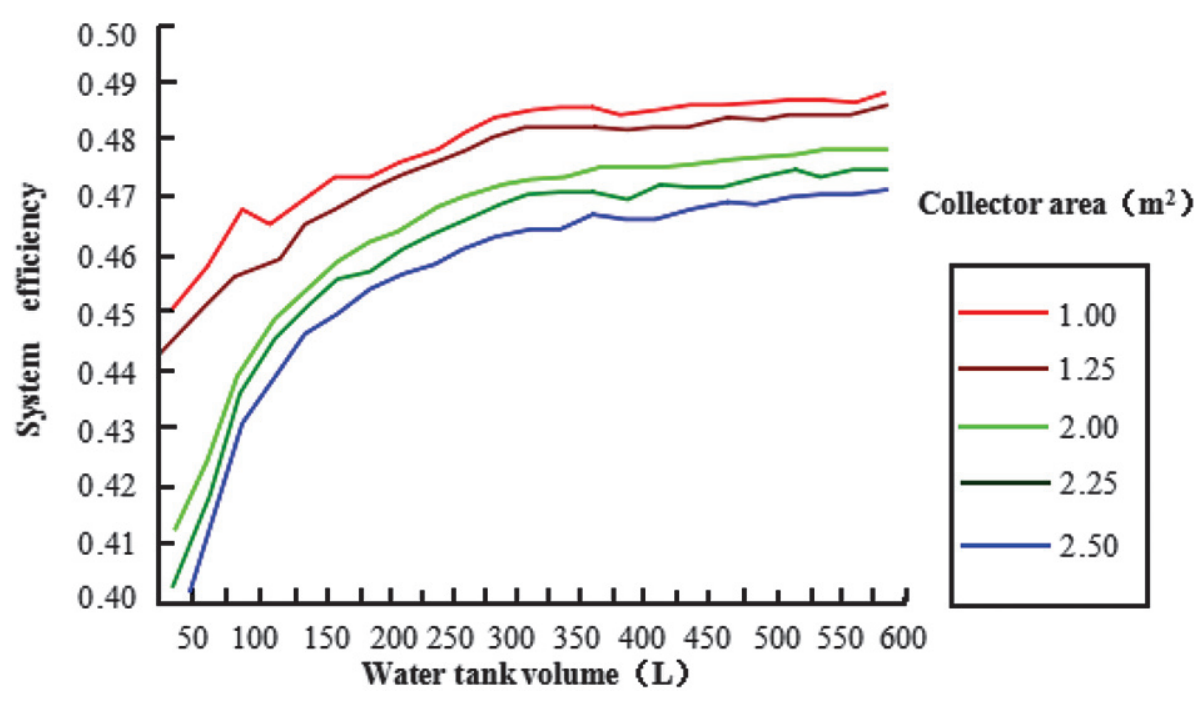

Fig.7: Influence of different heat collecting area and corresponding water tank volume on solar energy guarantee rate

collector, and the efficiency equation of the collector is $\eta=$ $0.62-5.51\left(t_{m}-t_{\alpha}\right) / I$. The system adopts the natural circulation direct type single water tank mode, and the storage hot water has auxiliary electric heating device to ensure the constant temperature of the water outlet.

The influence of the different collector area and the corresponding water tank volume on the system efficiency is shown in Fig.6. The influence of the different collector area and the corresponding water tank volume on the solar fraction is shown in Fig.7.

From the data in Figs. 6 and 7, conclusions can be drawn as follows:

1. In the case of a given collector area, the efficiency of the system increases with the water tank volume increasing, but when the volume of the tank increases to a certain extent, the efficiency of the system will change very slowly.

2. When the collector area is constant, the system efficiency is mainly related to the average water temperature through the collector, and the lower the average water temperature is, the higher is the efficiency.

3. The increase of the water tank will increase the water cycle; cycle of the whole water tank, and the amount of water in the water tank will increase, and the water temperature in the water tank will rise more slowly. As a result, the average water temperature through the collector decreases and the efficiency of the system increases.

4. Under certain heat collecting area, the solar fraction of the system increases with the increase of the water tank, which is easy to understand in the analysis of system efficiency. The higher the efficiency of the system is, the more solar energy will be used. In the case of constant water consumption, of course, the solar fraction will be higher.
5. Expected to guarantee a certain solar fraction, collector area must meet certain conditions, because a collector area has a maximum value of solar fraction. In the simulation process to find the system to meet the solar fraction above 0.5 , while the collector area is in need of more than 1.8 square meters.

When the solar fraction is above 0.5 , the heat collecting area should be 1.9 2.1 square meters, so that the corresponding water tank volume is 200L 80L, and the system efficiency is running at a higher level of $0.42 \sim 0.46$. Besides the efficiency of the system, the cost of the system should be considered in the selection of the volume of the water tank and the heat collecting area, that is to say, in the several schemes that meet the solar fraction. If the price of flat heat collector is calculated according to $1000 \mathrm{yuan} / \mathrm{m}^{2}$, the price of water tank is calculated according to 1300 yuan/tonne, then the system cost under different solar fraction can be obtained.

\subsection{EXPERIMENTAL ANALYSIS OF OPTIMIZATION OF FORCED CIRCULATION SYSTEM}

In this paper, a 7 storey house is taken as an example to design a solar hot water system which provides hot water for 24 hours. The residential building area is 1800 square meters, the total number of households is 20, and the population per household is assumed to be 3. Each person's daily hot water rating is: 50 degrees Celsius hot water, 50L (per person per day). Therefore, the system design water yield is: 50 degrees Celsius hot water, 3000L/day. An ordinary flat heat collector with a copper aluminum composite plate core is adopted in the collector. The system adopts a forced circulation direct double tank mode, and an auxiliary electric heating device is arranged in the heating water tank.

The heat collector is connected with as shown in Fig.8 parallel-series collection.

In addition to the heat collecting area and the water tank volume, the circulation pump flow needs to be also considered from the point of view of the forced system. In the simulation calculation, it is found that the flow rate of the pump has a great influence on the system efficiency. Therefore, it is essential to discuss the relationship between water flow and water tank volume in specific heat collecting area, with an area of 31.5 square meters in hot water circulating pump and flow volume of the water tank as the object of discussion. The effect of the different water tank capacity and the corresponding pump flow on the system efficiency is shown in Fig.9, and the effect of the different water tank capacity 
and the corresponding pump flow rate on the solar fraction is shown in Fig. 10.

From the results shown in Figs.9 and 10, conclusions can be drawn as follows:
1. When the collector area and the water tank volume is certain, with the increase of pump flow, system efficiency and solar fraction are first increased and then decreased, and when the small flow rate greatly increases, the

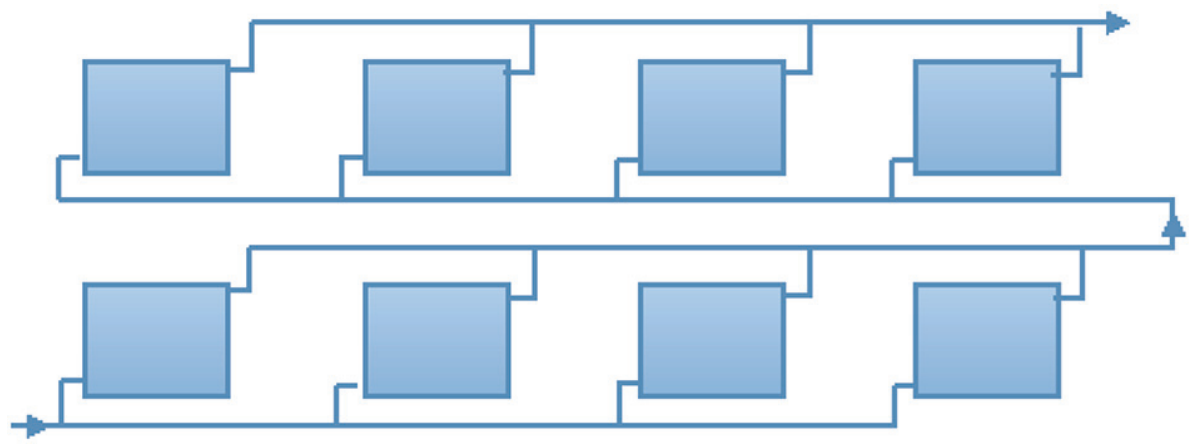

Fig.8: Parallel-series collection

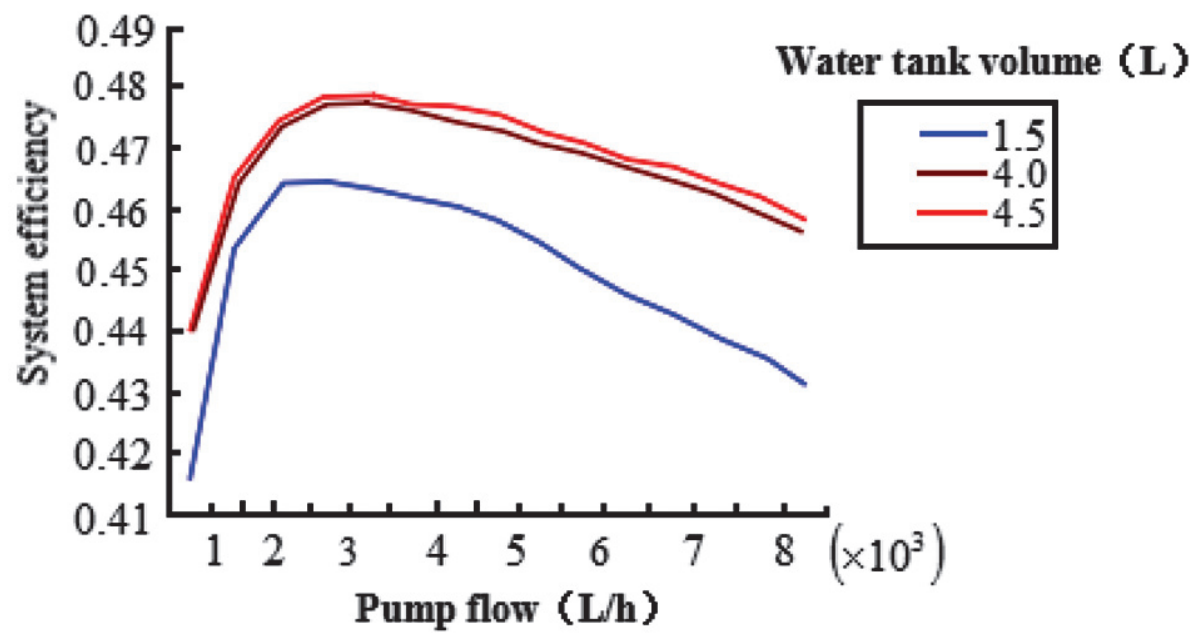

Fig.9: Influence of different water tank capacity and corresponding pump flow rate on system efficiency

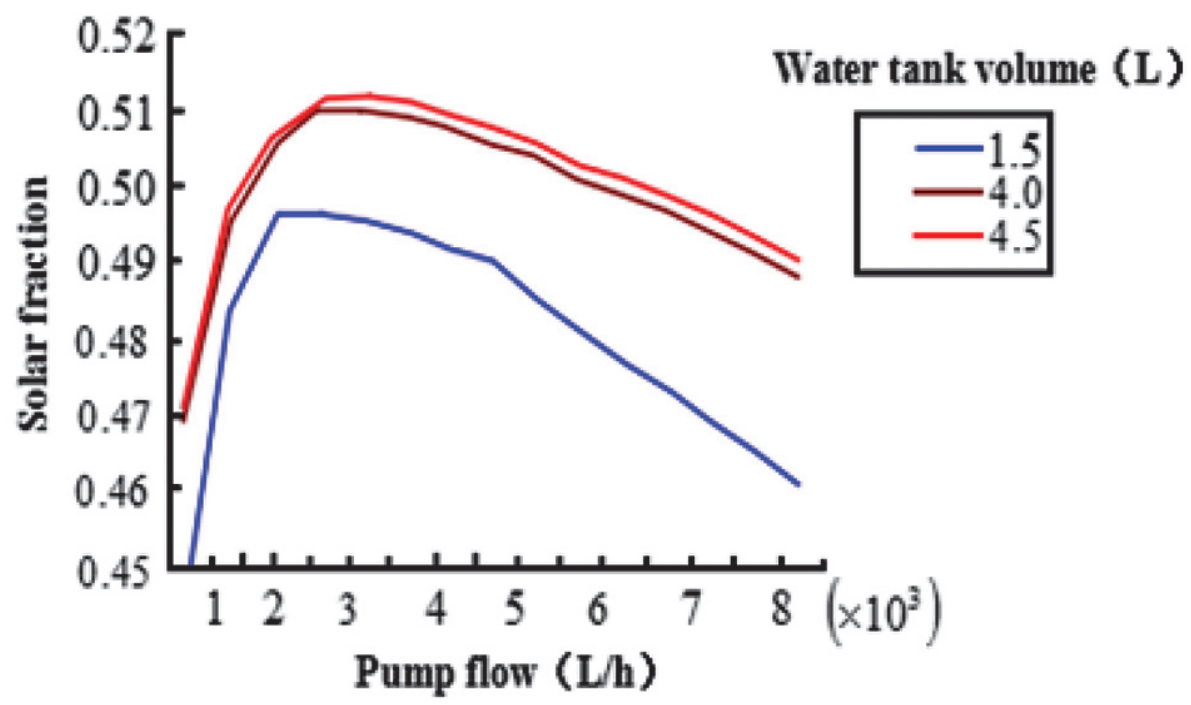

Fig.10: Influence of different water tank capacity and corresponding water pump flow rate on solar energy guarantee rate efficiency of the system has increased considerably. As the flow is large, the system reduces efficiency is reduced.

2. When the pump flow is very small, the hot water in collector can not be taken to the water tank, so that the collector of the water is always maintained at a high temperature. The increase of pump flow makes the set temperature heat exchanger decrease and the efficiency of the system increase.

3. When the pump flow is very large, the water in the water tank is circulated once in a short time, which makes the average water temperature of the collector flow higher and leads to the decrease of the efficiency.

4. When the heat collecting area and pump flow are under certain conditions, the system efficiency and solar fraction increases with the increase of the capacity of the tank, but with the water tank volume increasing to a certain extent, the increase range of system efficiency and solar fraction will be smaller and finally tends to a maximal value.

Therefore, to meet a certain guaranteed solar rate, collector area must be large enough. This is because in a certain area under the heat efficiency of the system, a maximum value will be got.

It is shown in Fig.11 that the influence of the pump flow and the volume of the water tank on the solar energy guarantee rate under the heat collecting area of 30 square meters

As can been seen from Fig.11, when the collector area is 30 square meters, the largest solar system can provide the solar fraction not more than 0.5 . When the tank volume is 4.5 cubic meters, the increase of the 


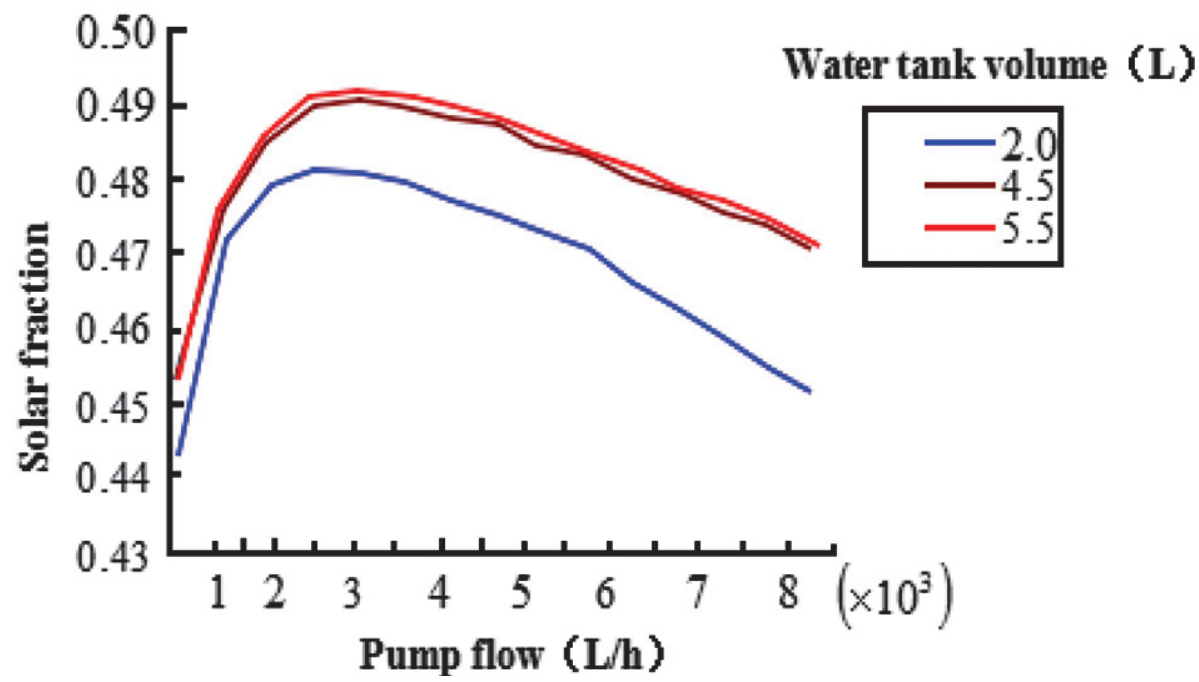

Fig.11: Influence of pump volume and volume of water tank on solar energy efficiency under $30 \mathrm{~m}^{2}$ heat collecting area tank volume and the heat collecting area. That is to say, among the several schemes to meet the solar fraction, the lowest cost is chosen. If the calculation of flat plate collector is in accordance with the price of 1000 yuan $/ \mathrm{m}^{2}$, the water tank in accordance with the price of 1300 yuan/tonne, the system costs can be obtained under different guarantee rates. As shown in Table 1, a systematic comparison of the three schemes is made.

As can be seen from Table 1, the cost of the three schemes is relatively close, because the three schemes meet the demand. However, considering the model of the existing flat plate collector in the market, the system efficiency of the water tank volume is very small. When the collector area and the water tank volume is certain, to meet certain solar fraction, there are two kinds of pump flow available, but from the point of cost, a small amount of water flow must be chosen.

\subsection{System COMparison of SOLAR ENERGy GUARANTEe Rate OF 0.5}

Natural circulation system: when the solar fraction is above 0.5 , the heat collecting area should be 1.9 2.1 square meters, so that the corresponding water tank volume is $200 \mathrm{~L} \sim 80 \mathrm{~L}$, and the system efficiency is higher than the $0.42 \sim 0.46$ level. Besides the system efficiency, the cost of the system should be considered in the selection of the water scheme with a heat collection area of 2 square meters was chosen.

Forced circulation system: a systematic comparison of the three heat collection areas is shown in Table 2

TABLE 1: (NATURAL CIRCULATION SYSTEM) SYSTEM COMPARISON OF SOLAR ENERGY GUARANTEE RATE OF 0.5

\begin{tabular}{cccc}
\hline $\begin{array}{c}\text { Collector } \\
\text { area }\left(\mathrm{m}^{2}\right)\end{array}$ & $\begin{array}{c}\text { Tank } \\
\text { volume }(\mathrm{L})\end{array}$ & $\begin{array}{c}\text { System } \\
\text { efficiency }\end{array}$ & $\begin{array}{c}\text { System } \\
\text { costs (yuan) }\end{array}$ \\
\hline $1.9 \mathrm{~m}^{2}$ & $193 \mathrm{~L}$ & 0.461 & 2151 yuan \\
$2.0 \mathrm{~m}^{2}$ & $110 \mathrm{~L}$ & 0.442 & 2143 yuan \\
$2.1 \mathrm{~m}^{2}$ & $80 \mathrm{~L}$ & 0.425 & 2204 yuan \\
\hline
\end{tabular}

TABLE 2: SYSTEMATIC COMPARISON OF THREE TYPES OF COLLECTOR AREA

\begin{tabular}{|c|c|c|c|c|c|c|c|c|c|c|c|}
\hline \multicolumn{4}{|c|}{ The collector area is $31.5 \mathrm{~m}^{2}$} & \multicolumn{4}{|c|}{ The collector area is $33.0 \mathrm{~m}^{2}$} & \multicolumn{4}{|c|}{ The collector area is $34.5 \mathrm{~m}^{2}$} \\
\hline A & B & $\mathrm{C}$ & $\mathrm{D}$ & A & B & $\mathrm{C}$ & $\mathrm{D}$ & A & B & $\mathrm{C}$ & $\mathrm{D}$ \\
\hline 1.8 & 2100 & 6687 & 40527 & 1.5 & 1500 & 4958 & 39908 & 1.2 & 1450 & 4729 & 40789 \\
\hline 2.0 & 1950 & 6312 & 40412 & 1.8 & 1400 & 4729 & 40069 & 1.5 & 1320 & 4437 & 40887 \\
\hline 2.3 & 1800 & 5904 & 40394 & 2.0 & 1350 & 4667 & 40267 & 1.8 & 1220 & 4333 & 41173 \\
\hline 2.5 & 1750 & 5750 & 40500 & 2.3 & 1300 & 4583 & 40573 & 2.0 & 1180 & 4295 & 41395 \\
\hline 3.0 & 1700 & 5646 & 41046 & 2.5 & 1250 & 4604 & 40854 & 2.3 & 1120 & 4270 & 41760 \\
\hline 3.5 & 1700 & 20325 & 41696 & 3.0 & 1200 & 4520 & 41420 & 2.5 & 1110 & 4270 & 42020 \\
\hline
\end{tabular}

Note: a means tank volume (M3); B represents pump flow (1/h); C represents pump power consumption for 15 years (\$); D represents cost of system; pump power consumption in 15 years (yuan)

TABLE 3: (FORCED CIRCULATION) SYSTEM COMPARISON OF SOLAR ENERGY GUARANTEE RATE OF 0.5

\begin{tabular}{ccccc}
\hline Collector area & Tank volume (L) & Pumping capacity & System efficiency & $\begin{array}{c}\text { System costs }+ \text { pump power } \\
\text { consumption in } 15 \text { years (yuan) }\end{array}$ \\
\hline $31.5 \mathrm{~m}^{2}$ & $2.3 \mathrm{~m}^{3}$ & $1800 \mathrm{~L} / \mathrm{h}$ & 0.468 & 40394 yuan \\
$33.0 \mathrm{~m}^{2}$ & $1.5 \mathrm{~m}^{3}$ & $1500 \mathrm{~L} / \mathrm{h}$ & 0.447 & 39908 yuan \\
$34.5 \mathrm{~m}^{2}$ & $1.2 \mathrm{~m}^{3}$ & $1450 \mathrm{~L} / \mathrm{h}$ & 0.427 & 40789 yuan \\
\hline
\end{tabular}


The data in Table 2 shows that when the heat collection area is constant, the pump flow must be reduced if the solar fraction is content and the tank volume is increased. However, when the tank volume increases to a certain extent, the water pump flow almost does not change any more. According to the principle that the cost of the pump and the cost of power consumption of the pump are lowest during the life of the system, the optimum configuration of the three heat collecting areas can be selected from Table 2, and the three configuration results are shown in Table 3.

As is shown in Table 3, in accordance with the principle that the system cost and life of the pump power consumption are lowest, the heat collection area of 33 square meters of the group configuration should be chosen.

\subsection{Conclusions}

On the basis of summarizing the solar energy construction technology, the article expounds the key technical links of them, from which it can be understood that solar energy building can be divided into passive solar energy building and active solar energy building. Subsequently, the technical principle of the natural circulation system, the direct connected system and the forced circulation system of the solar hot water system have been analyzed,. Finally, the natural circulation system and the forced circulation system have been simulated on the TRNSYS platform, and some suggestions have been made for the optimization of the system during the simulation process.

And conclusions can be drawn as follows:

1. The efficiency of solar water heating system of natural circulation and forced circulation increases with the increase of collector area and water tank volume, but the value of efficiency is maximum when the collector area is definite.

2. The efficiency of the forced circulation solar water heating system increases first and then decreases with the increase of the pump flow rate.

3. Natural cycle: taking into account of the existing model of flat plate collector in the market, the final selection of heat collection area is of 2 square meters of the program.
4. Forced circulation: in accordance with the principle that the system cost and life of the pump power consumption are lowest, the heat collection area of 33 square meters of the group configuration should be chosen.

\section{Acknowledgments}

This work is supported by the National Natural Science Foundation of China (no. 51674121), by the National Natural Science Foundation of Hebei Province (no. E2017209178), the National Natural Science Foundation of Hebei Education Department (no. QN2016088), and Graduate Student Innovation Fund of North China University of Science and Technology, Graduate Student Innovation Fund of Hebei Province (2017S03, CXZZSS2017071).

\section{References}

1. XIAO C Y, et al. (2008): Renewable energy and building energy conservation[J]. Technology Information of China. (20): 21-23.

2. WU J L, et al. (2014): Brief analysis of Solar thermal photovoltaic construction project and its example [J]. Chinese folk house. 2014 (4): 106-107.

3. LONG Y T, et al. (2014): Feasibility study of solar energy construction integration in Northern Shaanxi Province [J]. Shanxi architecture. 2014.40 (4):234-235.

4. REN R T, et al. (2011): Analysis of new energy building and its technology [J]. Building energy efficiency. 2011.39 (242): 31-35.

5. WANG C J, et al. (2007): Solar energy building design [M]. Beijing: China Construction Industry Press. 2007:43.

6. GAO Q. (2007): Integration of renewable energy utilization and building energy saving technology [j]. Journal of Changchun University of Technology. 2007 (28):146-149.

7. AO Y A, et al. (2013): Thermal performance analysis and simulation software development of solar building interior [J]. Journal of Shenyang Construction University. 2013.29 (2):327-332.

8. LI X R. (2004): Integration of distributed energy and architecture [J]. Energy saving and environmental protection. 2004 (10):10-13.

\section{JOURNAL OF MINES, METALS \& FUELS
SPECIAL ISSUE ON
Rs.500.00; £50.00 or \$80.00
For copies please contact:
The Manager
Books \& Journals Private Limited
Moon Plaza (2A, 2nd Floor), 62 Lenin Sarani, Taltala, Kolkata 700013・e-mail: bnjournals@gmail.com; pradipchanda@yahoo.co.uk}

Printed by Pradip Kumar Chanda at The Indian Press Pvt. Ltd. 93A Lenin Sarani, Kolkata 700013 and published by him for Books \& Journals Pvt. Ltd. from 62 Lenin Sarani, Kolkata 700013. 